\title{
Stability and Physical Properties of Emulsions Prepared with and without Soy Proteins
}

\author{
Allaoua Achouri, Youness Zamani \& Joyce Irene Boye \\ Agriculture and Agri-Food Canada, Food Research and Development Centre, \\ 3600 Casavant Boulevard West, St. Hyacinthe (Quebec) J2S 8E3, Canada \\ Tel: 1-450-768-3232Ｅ-mail: joyce.boye@agr.gc.ca
}

Received: November 13, $2011 \quad$ Accepted: November 22, $2011 \quad$ Published: February 1, 2012

doi:10.5539/jfr.v1n1p254

URL: http://dx.doi.org/10.5539/jfr.v1n1p254

\begin{abstract}
The ability of emulsifiers (gum arabic, starch and soy protein isolate (SPI)) and texture modifiers (gum tragacanth and carrageenan) alone and as a mixture with SPI to stabilize oil-in-water emulsions at high oil concentrations was studied. Parameters investigated included droplet size distribution, color $(\Delta \mathrm{E})$, viscosity and creaming stability. At $10 \%(\mathrm{w} / \mathrm{v})$ emulsifier to oil ratio, emulsions stabilized with gum arabic, starch and SPI had average oil droplet sizes lower than $1 \mu \mathrm{m}$. Increasing the oil content by two-fold (emulsifier/oil ratio of 10:20), increased the average droplet size of the gum arabic and SPI emulsions to 1.5 and $4.2 \mu \mathrm{m}$, respectively, while that of the starch emulsion remained unchanged. At 5\% oil concentration, gum tragacanth and carrageenan stabilized emulsions yielded two average droplet sizes of $0.5 \mu \mathrm{m}(52.7 \%)$ and $1.8 \mu \mathrm{m}(46.5 \%)$, and $0.5 \mu \mathrm{m}$ (48.8\%) and $1.7 \mu \mathrm{m}(46.6 \%)$, respectively. Increasing the oil concentration to $10 \%$ increased the particle size with fairly similar proportions. Gum arabic stabilized emulsions had lower $\Delta \mathrm{E}$ than starch and SPI (except at $20 \%$ oil content). $\Delta \mathrm{E}$ of carrageenan and tragacanth emulsion decreased significantly when used as a mixture with SPI. Droplet size strongly affected color. All concentrated emulsions exhibited shear-thinning behavior irrespective of oil, emulsifier type and concentration. SPI, followed by starch and gum arabic emulsions showed good stabilities over the 15 days storage period. Gum tragacanth and carrageenan emulsion stabilities were only improved when combined with SPI, particularly at 5\% oil concentration.
\end{abstract}

Keywords: Gums, Emulsions droplet size distribution, Color, Viscosity, Stability

\section{Introduction}

Emulsions form the basis of a wide variety of natural and manufactured materials used in the food, pharmaceutical and cosmetic industries (Becher 1985 and 1988; Schramm, 1992; Lin and Mei, 2000; McClements, 2005). Existing and new ingredients are regularly incorporated into food systems to improve their rheological, physicochemical and nutritional properties. These ingredients, however, may sometimes slowly degrade and lose their activity, undergo oxidation, react with components present in the food system which may limit their bio-availability, or change the colour or taste of a product (Schrooyen et al., 2001), making it necessary that they be stabilized.

One of the major concerns for emulsions is keeping the emulsion droplets uniformly distributed during storage and consumption (Chanamai and McClements, 2002). This has led the food industry and many researchers to investigate the ability of hydrocolloids and proteins to stabilize emulsion droplets against creaming, flocculation and coalescence, depending on their intended application. Previous studies have also shown that the stability of oil-in-water $(\mathrm{O} / \mathrm{W})$ emulsions depends on both the type and concentration of ingredients contained in the emulsion as well as processing and storage conditions (McClements, 1999). Concentrated emulsions are a unique class of $\mathrm{O} / \mathrm{W}$ emulsion in that they can be consumed in highly diluted form (low viscosity fluids such as milk and fruit juice beverages) or in their original concentrated form (such as in creams, margarine or butter). Thus, the emulsion must have a significant degree of stability in both the concentrated and diluted forms (Tan, 1990).

At present, gum arabic is one of the most widely used biopolymers in foods and beverages (Randall et al., 1988; Williams et al., 1990; Garti and Reichman, 1993). Its arabino galacto protein (AGP) component is responsible for its unequalled emulsifying properties, including the ability to form stable emulsion over a wide $\mathrm{pH}$ range and 
in the presence of electrolytes (Nussinovitch, 1997; Islam et al., 1997; Buffo et al., 2001). Nevertheless, there have been many efforts to find alternative sources of natural emulsifiers, because gum arabic is very expensive and its supply and quality can be somewhat erratic (Chanamai and McClements, 2002). Starches are now widely used in dairy-based food products because of their good emulsifying properties, and have been identified as promising replacements for gum arabic (Trubiano, 1995). Other alternative gums including tragacanth (Imeson, 1992) and $\lambda$-carrageenan (Huang et al., 2001) have been reported as effective thickeners and stabilizing agents (Stephen 1990). Proteins, including whey and soy are emulsifiers that can alter both emulsion droplet charge and interfacial membrane thickness in oil-in-water emulsions (Kim et al., 1996; Keogh and O'Kennedy, 1999; Kulmyrzaev et al., 2000; Singh and Ye 2000) and form stable films against oxidation (Djordjevic et al., 2008; McClements, 2004). Although the aforementioned molecules have been extensively studied and widely used as active ingredients in milk-based products (ice cream, milk beverages, yogurt and milk puddings), very little is found in the literature about their ability to stabilize concentrated emulsions containing higher oil concentration $(>10 \%)$. In addition, factors that could contribute to the emulsion stabilization/destabilization such as, the type of hydrocolloid, the possible combination of hydrocolloid with protein, and the concentration of oil to be dispersed have not been reported.

There is growing interest in the formulation of value-added products containing health ingredients (i.e., Omega-3, vitamins and minerals, etc.,) for the functional food market. Such emulsion concentrates can be useful as feedstock emulsions for other suspension emulsions as well as constituting a stable oil-in-water emulsion delivery. Therefore, understanding and monitoring the factors that influence the stability and shelf-life of prepared emulsion matrices is critical for their continued success in the market place.

The present work was aimed at (1) evaluating the ability of emulsifiers, protein and texture modifiers alone and as a mixture with soy proteins to prepare emulsion concentrates, and (2) investigating the characteristics of the emulsion concentrates (i.e., droplet size distribution, color and viscosity of the dispersed oil-in-water emulsions) and studying their stability over time.

\section{Materials and Methods}

\subsection{Materials}

Starch was obtained from the National Starch and Chemical Co. (Boucherville, Qc, Canada). Gum arabic, gum tragacanth and $\lambda$-carrageenan were kindly donated by Frutarom Inc. (NJ, USA) and refined vegetable oil was purchased from the local market. Soy protein isolate (PRO-FAM 873) was purchased from ADM Co., USA (protein content $90 \%$, fat $1 \%$, ash $4 \%$, and moisture $6 \%$ ). Cow's milk (3.25\% fat) was purchased from the local supermarket and used as a reference for color measurements. All solutions were prepared using distilled water, and all measurements were taken at $25^{\circ} \mathrm{C}$ unless otherwise stated.

\subsection{Preparation of solutions}

In general, concentrated oil-in-water emulsions are prepared at emulsifier-to-oil ratio of 1:1 or 1:2 (Lee \& Tadros, 1982). For this study, dispersed solutions of the emulsifiers (gum arabic and starch, at $10 \% \mathrm{w} / \mathrm{v}$ ); protein (SPI, at $10 \% \mathrm{w} / \mathrm{v}$ ), texture modifiers (gum tragacanth and carrageenan at $0.025 \%$ and $0.1 \% \mathrm{w} / \mathrm{v}$, respectively) and SPI-tragacanth $(10 \%+0.025 \% \mathrm{w} / \mathrm{v})$ and SPI-carrageenan $(10 \%+0.1 \% \mathrm{w} / \mathrm{v})$ mixtures were prepared in distilled water and allowed to hydrate overnight. The $\mathrm{pH}$ of these solutions were adjusted to $6.5 \pm 0.1$ before use. Gum tragacanth and carrageenan solutions were prepared at very low concentrations $(0.025$ and $0.1 \% \mathrm{w} / \mathrm{v}$, respectively) due to their high viscosities and their low permissible levels of utilization in the food industry.

\subsection{Preparation of emulsion concentrates}

Table 1 reports the ratios used for the preparation of the different emulsion concentrates. $10 \%$ and $20 \%$ oil-in-water emulsions were prepared using gum arabic, starch and SPI. Emulsion concentrates with tragacanth and carrageenan alone and in mixture with SPI were prepared at 5\% and 10\% oil-in-water emulsions. Coarse emulsions were first prepared using the rotor system Polytron PT 10/35 (Kinematica AG, Switzerland) for 1 minute, then homogenization of the coarse emulsions was achieved with a pressure valve homogenizer (Emulsifex-C5 Avestin, Don Reid Drive, Ontario, Canada) for $60 \mathrm{~s}$ at a pressure of 200 bar (3000 psi) and were analyzed for stability, viscosity and color.

\subsection{Quickscan measurements}

Stability of the emulsions was monitored using a Coulter Quickscan ${ }^{\mathrm{TM}}$ turbidity analyzer (Fullerton, USA) following the method described by Chanamai and McClements (2000). Emulsions (5 mL) were placed into flat-bottomed cylindrical glass tubes $(100 \mathrm{~mm}$ height, $10-\mathrm{mm}$ internal diameter) and introduced into the Quickscan machine. At $\mathrm{t}=0$, the instrument measures the back scattering and/or transmission of monochromatic 
light $(\lambda=850 \mathrm{~nm})$ from the sample (as a function of its height) by scanning vertically along the cylinder sample cell. Two kinds of light scattering/transmission modifications were detected and plotted by the Coulter Quickscan. The test tubes were then stored at $4{ }^{\circ} \mathrm{C}$ and the stability of the emulsions was monitored over time (during a 15 days storage period). For curve interpretation, the decreases or increases of particular areas of the graphs represent particle migration to the top or bottom of the sample indicating creaming or sedimentation. Second, decreases in the overall back scatter values along the length of the graph indicate particle or aggregate size variation indicating coalescence or flocculation. The back-scattering profile at $\mathrm{t}=0$ was considered as the reference to analyze the stability of the system.

\subsection{Droplet size distribution and Zeta-Potential}

Emulsion droplet size distribution was determined by the laser light-scattering method using a Zetasizer 4 Malvern (Malvern Instruments, Malvern, UK). The instrument uses photon correlation spectroscopy (PCS) to measure particle size in constant random thermal or Brownian motion. This motion causes the intensity of the light scattered from the particles to vary with time. Large particles move slowly than small ones, so that the rate of fluctuation of the light scattered from them is also slower. PCS uses the rate of change of these light fluctuations to determine the size distribution of the particles scattering light. The particle diameter range and number of photon counts per second [kilo Count per second ( $\mathrm{kCps})$ ] were evaluated at room temperature when the volume fraction of oil in the diluted emulsion was about 1:4000 for all the cases. The emulsions were analyzed right after preparation in triplicate and results were expressed in percentage of volume of sample occupied by particles of a similar size class. The zeta-potential was determined by measuring the direction and velocity that the droplets moved in the applied electric field.

\subsection{Color measurements}

The color of the prepared emulsion concentrates was measured following the method of Chantrapornchai et al. (1998), on an instrumental colorimeter (Labscan II, Hunter Associates Laboratory, Reston, VA), which was calibrated using a white color standard tile with tristimulus values: $X=78.38, Y=83.21$, and $Z=87.41$ (Standard No. LS-13593, Hunter Associated Laboratory). A fixed amount of emulsion sample was poured into the measurement cell and measured. The instrument reports the color of the samples in terms of the $L, a, b$ color space system, where, $L$ represents the lightness, $a$ and $b$ are color coordinates: $L, 0$ (black) to 100 (white); $a,-80$ (green) to 100 (red); $b,-80$ (blue) to 70 (yellow) (Francis and Clydesdale, 1975). The data is also represented in terms of Chroma (C) and $\Delta E$ which is a measure of the difference in optical properties between a sample and a reference emulsion (milk):

$C=\left(a^{2}+b^{2}\right)^{1 / 2}$ and $\Delta E=\left((\Delta L)^{2}+(\Delta a)^{2}+(\Delta b)^{2}\right)^{1 / 2}$, where $\Delta L, \Delta a$ and $\Delta b$ are the differences in the specified tristimulus coordinate between the sample and the cow's milk (3.25\% fat) used as reference.

\subsection{Rheological measurements}

Viscosity measurements were performed following the procedure described by Anton et al. (2001), using a rheometer (AR 1000-N, TA Instrument, Newcastle, DE), with the following cone geometry: acrylic $2^{\circ}$ cone angle, $6.0 \mathrm{~cm}$ diameter, $46 \mu \mathrm{m}$ truncation. The temperature was maintained at $22{ }^{\circ} \mathrm{C}$ in all the experiments. The torque vs. angular velocity data, were converted first to shear stress vs. shear rate, and to apparent viscosity vs. shear rate, using TA software "Rheology Advantage Data Analysis" (TA Instrument, Newcastle, DE). The apparent viscosity was determined from the equation: $\sigma=\mathrm{K} \gamma^{\mathrm{n}}$ where, $\sigma$ is sheer stress $(\mathrm{Pa}), \gamma$ is the shear rate $\left(\mathrm{sec}^{-1}\right), \mathrm{K}$ is the consistency index, and $\mathrm{n}$ is the flow behaviour index.

\subsection{Statistical analysis}

All experiments were conducted in triplicate and reported as means \pm standard deviations. Statistical analyses were performed using $t$-test with a confidence interval of $95 \%$.

\section{Results and Discussion}

\subsection{Droplet size distribution and zeta potential of prepared emulsion concentrates}

\subsubsection{Emulsifiers versus SPI}

The oil droplet size distribution of the prepared emulsions is presented in Table 2. Emulsion concentrates stabilized with gum arabic and soy protein isolate (SPI) (with emulsifier/oil ratio of 10:10) both showed an average droplet size of $0.7 \mu \mathrm{m}$. Increasing the oil content by two-fold (emulsifier/oil ratio 10:20) resulted in a significant $(p<0.05)$ increase in the average droplet particle size for gum arabic $(1.45 \mu \mathrm{m})$ and SPI $(4.17 \mu \mathrm{m})$ emulsions. These large particles are probably the result of droplet aggregation (flocculation). Similar increases in particle size have been reported at neutral $\mathrm{pH}$ in hydrocarbon oil-in-water emulsions stabilized by 
$\beta$-lactoglobulin (Kim et al., 2002). Protein surface denaturation increases the surface hydrophobicity of emulsion droplets, which increases the hydrophobic attraction between droplets (Fang and Dalgleish, 1997). The average oil droplet size for the starch-stabilized emulsion was smaller $(0.4 \mu \mathrm{m}$ and $0.45 \mu \mathrm{m}$ at 10 and $20 \%$ oil concentrations, respectively). These results suggest that starch was more effective at producing small droplets during homogenization than gum arabic and SPI at both oil concentrations.

Measurements of zeta potential (the electrical charge of the droplets), along with particle size, can be used to predict the stability of fat emulsions. Theoretically, a high negative zeta potential prevents aggregation of the emulsion droplets and increases stability through electrostatic repulsion. The zeta potential values of starch-stabilized emulsions at different oil ratios were lower (less negative) than the zeta potentials of gum arabic and SPI. Increasing the oil content to $20 \%$ had no noticeable effect on the zeta potential of these emulsions.

\subsubsection{Texture modifiers}

Gum tragacanth and carrageenan stabilized emulsion concentrates prepared with $10 \%$ oil content resulted in average droplet sizes of $0.7 \mu \mathrm{m}$ and $4.4 \mu \mathrm{m}$ for gum tragacanth, and $0.5 \mu \mathrm{m}$ and $2 \mu \mathrm{m}$ for carrageenan. Each droplet size represented $\sim 50 \%$ of the volume of the emulsion sample. These emulsions, however, showed a thicker consistency (mayonnaise-like consistency). Reducing the oil content by half (to $5 \%$ ) and maintaining the same hydrocolloid concentration, resulted in a more fluid emulsion with significantly $(p<0.05)$ lower droplet sizes; $0.5 \mu \mathrm{m}$ and $1.8 \mu \mathrm{m}$ for gum tragacanth, and $0.5 \mu \mathrm{m}$ and $1.7 \mu \mathrm{m}$ for carrageenan. The proportions of the particle distribution did not change.

Due to their anionic nature, gum tragacanth and carrageenan emulsions showed higher negative zeta potentials; however, for some reason these emulsions were very unstable as revealed by their Quickscan graphs (Figure 3).

\subsubsection{SPI-texture modifiers mixtures}

When mixed with soy protein isolate, the SPI-gum tragacanth stabilized emulsion with $5 \%$ oil content gave lower average droplet sizes, while SPI-carrageenan had larger average droplet sizes at both emulsifier/oil ratios. This trend was expected because, the SPI-carrageenan complex showed a higher tendency to self-aggregate (visual observation). These aggregates could have been emulsion droplets held together by electrostatic carrageenan bridges (formation of carrageenan-protein complexes) (Dickinson and Stainsby, 1988), or due to droplet aggregation (flocculation or coalescence).

When mixed with soy protein isolate, the zeta potential of the droplets of SPI-tragacanth and SPI-carrageenan-stabilized emulsion concentrates decreased markedly (became less negative) and was almost similar to the droplet charge of emulsion stabilized with SPI alone. This result suggests that $\lambda$-carrageenan molecules may have been only weakly bound with soy protein molecule at this $\mathrm{pH}(6.5)$ of the emulsion concentrates. Ledward (1994) and Ward-Smith et al. (1994) reported that strength of the electrostatic interactions between proteins and polysaccharides is dependent on the sign, number, and distribution of ionizable groups on the molecules at specific $\mathrm{pH}$ values.

\subsection{Stability analysis of prepared emulsion concentrates}

Quickscan analysis allows for the evaluation of various types of instability phenomena, normally due to differences in density between the dispersed and the continuous phases. This includes creaming, sedimentation and particle size variation, which could be reversible (flocculation) or irreversible (coalescence). Figure 1 shows an example of a typical Quickscan profile showing different instability phenomenon which allows a macroscopic visualization of the stability of concentrated dispersions (Bru et al., 2004).

\subsubsection{Stability of emulsion concentrates prepared with emulsifiers}

Stabilities of the emulsion concentrates prepared with the different emulsifiers (gum arabic, starch, SPI) are presented in Figure 2. The results indicated that the SPI emulsion concentrates (at both $10 \%$ and $20 \%$ oil concentrations) showed the highest stability as evidenced by the stability of its backscattering flux during storage. Starch, on the other hand, showed a slight decrease in backscattering across the height of the sample which is characteristic of a flocculation phenomenon (i.e., particle aggregation) and likely due to an increase of the size of the particles,. At $20 \%$ oil concentration, the emulsion stability improved except for a noticeable decrease of the backscattering level at the top of the sample, indicative of creaming. For gum arabic, the backscattering flux decreased at the bottom of the sample tube due to a decrease in particle concentration (clarification) whereas it increased at the top of the sample due to an increase of the concentration of the dispersed phase (creaming). 


\subsubsection{Stability of emulsion concentrates prepared with texture modifiers}

As shown in Figure 3, concentrated emulsions stabilized with carrageenan $(0.1 \%)$ and gum tragacanth $(0.0125 \%)$ alone at $10 \%$ oil content were very unstable and resulted in phase separation. From the backscattering and/or transmission fluxes of tragacanth and carrageenan concentrated emulsions, it was observed that the level of backscattering decreased across the height of the sample tube due to an increase of the size of the particles, which is characteristic of coalescence. Carrageenan concentrated emulsions also exhibited creaming phenomena at the top of the sample as evidenced by an increase in the peak thickness of the backscattered light. Garti and Reichman (1993) in an earlier review reported that not all hydrocolloids act as good emulsifiers. Gum arabic and some proteins (e.g., $\beta$-lactoglobulin, soy proteins) are good emulsifiers, whereas gum tragacanth, carrageenan, xanthan gum and galactomannans have limited surface activity and are more effective as stabilizers (Dickinson and Stainsby, 1988).

\subsubsection{Stability of emulsion concentrates prepared using a mixture of SPI and other texture modifiers}

Using a combination of SPI with either gum tragacanth or carrageenan improved the stability of the emulsions concentrates at $10 \%$ oil concentration (Figure 3). Reducing the oil content in the concentrated emulsions to $5 \%$ increased their stabilities. This is in good agreement with the findings of Gu et al. (2004, 2005a,b) who reported that oil-in-water emulsions prepared with $\beta$-lactoglobulin-l-carrageenan had higher stability than emulsions stabilized with either $\beta$-lactoglobulin or -carrageenan solutions alone. They explained that in these systems a two-component interfacial membrane is produced, leading to the formation of a two-layered interface surrounding the droplets. Emulsions stabilized by two-layered membranes reportedly have better stability against environmental stresses (such as thermal processing, freeze-thaw cycling, lipid oxidation, and high ionic strengths) than those stabilized by single-layered membranes (McClements, 2004).

In general, visual inspection of the samples showed that concentrated emulsions prepared using gum arabic, starch and SPI were stable compared to tragacanth and carrageenan over the 15 days of storage (Figure 4).

\subsection{Color and viscosity analyses}

\subsubsection{Color and viscosity of emulsion concentrates prepared with emulsifiers}

The results of color measurements ( $L, a, b$ tristimulus values; color intensity, chroma $(C)$; and color difference relative to reference $(\Delta E)$ ) of the emulsion concentrates are presented in Table 3. Emulsion concentrates stabilized with gum arabic (emulsifier/oil ratio of 10:10) had lower $\Delta E$ value than for the starch and SPI samples. A large decrease in the $\Delta E$ of SPI-stabilized emulsion (i.e., from 13.06 to 4.98) was observed when the oil concentration was increased from 10 to $20 \%$. As the average droplet size increased from $0.7 \mu \mathrm{m}$ to $4.17 \mu \mathrm{m}$ for SPI emulsion (Table 2), the $L, a$ and $b$ values decreased resulting in the lowering of the $\Delta E$ value. In their earlier work, Chantrapornchai et al. $(1998,2001)$ reported that as the droplet size increases, the scattering efficiency of the droplets decreases, which causes a reduction in lightness (lower $L$ value) and an enhancement of color. However, increasing oil concentration may sometimes negatively affect emulsion color (by increasing the $\Delta E$ value) if the two other tristimulus coordinates ( $a$ and $b$ ) do not decrease with the increase in the particle size; this was observed with gum arabic and starch where the chroma value (C) increased from 12.4 to 16.1 and from 12.7 to 14.8 , respectively. In fact, absorption of the light wave by the emulsion is largely responsible for 'chromaticness' (blueness, greenness, redness, etc.) which is strongly related to $a$ and $b$ values (McClements, 1998).

Viscosity measurements of the emulsion concentrates are presented in Table 3. The emulsion concentrates stabilized with gum arabic, starch and SPI at both oil concentrations (10 and $20 \%$ ) exhibited a decrease in viscosity with increasing shear rate, reflecting the pseudoplastic (shear thinning) nature of these emulsions. SPI showed higher viscosity than gum arabic and starch. Increasing the oil concentration to $20 \%$ resulted in an increase in viscosity, probably due to the increase in particle as reported previously (Table 2). Results reported by Chanamai and McClements (2002) suggest that the rheology of concentrated emulsions (viscosity) is fairly dependent on droplet concentration, size and shear rate, as well as the electrostatic repulsion between droplets.

3.3.2 Color and viscosity of emulsion concentrates prepared with texture modifiers

Gum tragacanth and carrageenan stabilized emulsions showed higher $\Delta E$ values at $10 \%$ oil concentration. Their poor emulsifying properties resulted in oil droplet coalescence, oil phase separation at the surface of the emulsion, which increased the tristimulus values ( $a$ and $b$ ) and, consequently, the $\Delta E$ and Chroma values. Decreasing the oil content to $5 \%$ decreased the $\Delta E$ values but did not improve their stabilities. The viscosities of these emulsion concentrates were also higher due to the thickening effect of gum tragacanth and carrageenan. Interestingly, when these two hydrocolloids were each used separately in combination with soy protein isolate, 
the SPI/gum tragacanth and SPI/carrageenan stabilized emulsions resulted in the lowest $\Delta E$ value and, consequently, the whitest emulsion color. Gu et al. (2005a,b), have reported that, in addition to color, emulsions formed by combining protein and polysaccharides are highly stable and resistant to a broad range of environmental stresses (such as $\mathrm{pH}$, ionic strength, and thermal processing).

\section{Conclusion}

The stability of oil-in-water emulsions was strongly influenced by the droplet size, charge and concentration. Oil droplet size lower than $1 \mu \mathrm{m}$ and higher zeta potential was required for improved stability. Under the studied conditions, concentrated emulsions prepared using the three emulsifiers; SPI, starch and gum arabic (with emulsifier/oil ratios of 10:10) were the most stable over the 15 days storage period. Concentrated emulsions stabilized with texture modifiers (gum tragacanth and carrageenan) showed several instabilities including clarification, particle size variation and creaming. Combination of SPI with either gum tragacanth or carrageenan improved the stability and color of the concentrated emulsions, particularly at $5 \%$ oil concentration. Overall the results indicated that emulsions stabilized by SPI and starch had better stability and could be promising replacements for gum arabic in food application due to their stable composition, availability and relatively low price. Many beverages are made from concentrated emulsions, which are diluted in aqueous solutions in order to simplify production processes and costs. Thus, the results of this study could prove useful in helping improve our understanding of how colloidal instabilities arise in emulsions and how they could be controlled in order to improve the quality of finished products.

\section{References}

Anton, M., Chapleau, N., Beaumal, V., Delepine, S., \& de Lamballerie-Anton. (2001). Effect of high-pressure treatment on rheology of oil-in-water emulsions prepared with hen egg yolk. Innovative Food Science and Emerging Technologies, 2, 9-21. http://dx.doi:10.1016/S1466-8564(00)00036-9

Becher, P. (1985). Encyclopedia of emulsion technology, Volume 2, Applications, New York: Marcel Dekker.

Becher, P. (1988). Encyclopedia of emulsion technology, Volume 3, Basic Theory, Measurement, Applications, New York: Marcel Dekker.

Bru, P., Brunel, L., Buron, H., Cayré, I., Ducarre, X., Fraux, A., Mengual, O., Meunier, G., De Sainte Marie, A., $\&$ Snabre, P. (2004). Particle size and rapid stability analyses of concentrated dispersions. ACS document, 1-15.

Buffo, R. A., Reineccius, G. A., \& Oehlert, G. W. (2001). Factors affecting the emulsifying and rheological properties of gum acacia in beverage emulsions. Food Hydrocolloids, 15, 53-66. http://dx.doi:10.1016/S0268-005X(00)00050-3

Chanamai, R., \& McClement, D. J. (2000). Dependence of creaming and rheology of monodisperse oil-in-water emulsions on droplet size and concentration. Colloids and Surfaces A: Physicochemical Engineering Aspects, $172,79-86$.

Chanamai, R., \& McClements, D. J. (2002). Comparison of gum Arabic, modified starch and whey protein isolate as emulsifiers: Influence of $\mathrm{pH}, \mathrm{CaCl}_{2}$ and temperature. Journal of Food Science, 67, 120-125. http://.dx.doi:10.1111/j.1365-2621.2002.tb11370.x

Chantrapornchai, W., Clydesdale, F. M., \& McClement, D. J. (1998). Influence of droplet size and concentration on the color of oil-in-water emulsions. Journal of Agricultural and Food Chemistry, 46, 2914-2920. http://dx.doi:10.1021/jf980278z

Chantrapornchai, W., Clydesdale, F. M., \& McClement, D. J. (2001). Influence of flocculation on optical properties of emulsions. Journal of Food Science, 66, 464-469. http://dx.doi:10.1111/j.1365-2621.2001.tb16130.x

Dickinson, E., \& Stainsby, G. (1988). Emulsion stability. In E. Dickinson, \& G. Stainsby (Eds.). Advances in Food Emulsions and Foams (pp. 1-44). Elsevier.

Djordjevic, D., Cercaci, L., Alamed, J., McClements, D. J., \& Decker, E. A. (2008). Stability of citral in protein and gum Arabic-stabilized oil-in-water emulsions. Food Chemistry, 106, 698-705. http://dx.doi:10.1016/j.foodchem.2007.06.033.

Fang, Y., \& Dalgleish, D. G. (1997). Conformation of $\beta$-lactoglobulin studied by FTIR: Effect of pH, temperature, and adsorption to the oil-water interface. Journal of Colloid Interface Science, 196, 292-298. http://dx.doi:10.1006/jcis.1997.5191 
Francis, F. J., \& Clydesdale, F. M. (1975). Food colorimetry: Theory and applications. Westport, Conn.: AVI Publishing.

Garti, N., \& Reichman, D. (1993). Hydrocolloids as food emulsifiers and stabilizers. Food Structure, 12, 411-426.

Gu, Y. S., Decker, E. A., \& McClements, D. J. (2004). Influence of pH and 1-carrageenan concentration on properties of $\beta$-lactoglobulin stabilized oil-in-water emulsions. Journal of Agricultural and Food Chemistry, 52, 3626-3632. http://dx.doi:10.1021/jf0352834

Gu, Y. S., Decker, E. A., \& McClements, D. J. (2005). Influence of pH and carrageenan type on properties of $\beta$-lactoglobulin stabilized oil-in-water emulsions. Food Hydrocolloids, 19, 83-91. http://dx.doi:10.1016/j.foodhyd.2004.04.016

Gu, Y. S., Reignier, L., \& McClements, D. J. (2005). Influence of environmental stress on stability of oil-in-water emulsions containing droplets stabilized by $\beta$-lactoglobulin-1- carrageenan membranes. Journal of Colloid and Interface Science, 286, 551-558. http://dx.doi:10.1016/j.jcis.2005.01.051

Huang, X., Kakuda, Y., \& Cui, W. (2001). Hydrocolloids in emulsions: particle size distribution and interfacial activity. Food Hydrocolloids, 15, 533-542. http://dx.doi:10.1016/S0268-005X(01)00091-1

Imeson, A. P. (1992). Exudate gums. In A. Blackie \& P, Glasgow (Ed. A. P. Imeson). Thickening and Gelling Agents for Food (pp. 66-97). London: Blackie Academic and Professional.

Islam, A. M., Phillips, G. O., Sljivo, A., Snowden, M. J., \& Williams, P. A. (1997). A review of recent developments on the regulatory, structural and functional aspects of gum Arabic. Food Hydrocolloids, 11, 493-505. http://dx.doi:10.1016/S0268-005X(97)80048-3

Keogh, M. K., \& O'Kennedy, B. T. (1999). Milk fat microencapsulation using whey proteins. International Dairy Journal, 9, 657-663. http://dx.doi:10.1016/S0958-6946(99)00137-5

Kim, H. J., Decker, E. A., \& McClement, D. J. (2002). Impact of protein surface denaturation on droplet flocculation in hexadecane oil-in-water emulsions stabilized by beta-lactoglobulin. Journal of Agricultural and Food Chemistry, 50, 7131-7137. http://dx.doi:10.1021/jf020366q

Kim, Y. D., Morr, C. V., \& Schenz, T. W. (1996). Microencapsulation properties of gum Arabic and several food proteins: Liquid orange oil emulsion particles. Journal of Agricultural and Food Chemistry, 44, 1308-1313. http://dx.doi:10.1021/j9950391e

Kulmyrzaev, A., Chanamai, R., \& McClements, D. J. (2000) Influence of $\mathrm{pH}$ and $\mathrm{CaCl}_{2}$ on the stability of dilute whey protein stabilized emulsions. Food Research International, 33, 15-20. http://dx.doi:10.1016/S0963-9969(00)00018-1

Ledward, D. A. (1994). Protein-polysaccharides interactions. In N. S. Hettiarachchy, \& G. R. Ziegler (Eds.). Protein Functionality in Food Systems (pp. 225-259). New York: Marcel Dekker.

Lee, G. W. J., \& Tadros, T. F. (1982). Formation and stability of emulsions produced by dilution of emulsifiable concentrates. Part II. The influence of surfactant concentration on the stability of oil-in-water emulsions. Colloids and Surfaces. 5, 117-127. http://dx.doi:10.1016/0166-6622(82)80067-x

Lin, K. W., \& Mei, M. Y. (2000). Influences of gums, soy protein isolate, and heating temperatures on reduced-fat meat batters in a model system. Journal of Food Science, 65, 48-52.

http://dx.doi:10.1111/j.1365-2621.2000.tb15954.x

McClements, D. J. (1998). Analysis of food emulsions. In S. S. Nielson, \& M. D. Gaitheburg, (Eds.). Food analysis (pp. 571-585). Aspen.

McClements, D. J. (1999). Food Emulsions: Principles, Practice and Techniques. (1rst ed.). Boca Raton, Florida, CRC Press.

McClements, D. J. (2004). Role of hydrocolloids as emulsifiers in foods" In P.A. Phillips, \& G. O. Williams (Eds.). Gums and stabilizers for the food industry (pp. 381-393). Royal Society of Chemistry. Cambridge, UK. Special Publication No. 294.

McClements, D. J. (2005). Food emulsion: Principles, practice and techniques. (2 ${ }^{\text {nd }}$ ed.). Boca Raton, FL, CRC Press.

Nussinovitch, A. (1997). Hydrocolloid applications: gum technology in the food and other industries, London: Blackie Academic \& Professional. 
Randall, R. C., Phillips, G. O., \& Williams, P. A. (1988). The role of the proteinaceous component on the emulsifying properties of gum Arabic. Food Hydrocolloids, 2, 131-140. http://dx.doi:10.1016/S0268-005X(88)80011-0

Schramm, L. L. (1992). Emulsions: Fundamentals and applications in the petroleum industry, Washington, D.C: American Chemical Society. http://dx.doi.org/10.1021/ba-1992-0231

Schrooyen, P. M. M., van der Meer, R., \& De Kruif, C. G. (2001). Microencapsulation: its application in nutrition. Proceedings of the Nutrition Society, 60, 475-479. http://dx.doi:10.1079/PNS2001112

Singh, H., \& Ye, A. (2000). Influence of calcium chloride addition on the properties of emulsions stabilized by whey protein concentrate. Food Hydrocolloids, 14, 337-346. http://dx.doi:10.1016/S0268-005X(00)00010-2

Stephen, A. M. (1990). Structure and properties of exudate gums. In G. O. Phillips, D. J. Wedlock, \& P. A. Williams (Eds.). Gums and Stabilizers for the Food Industry, Vol. 5, (pp 3-16). Oxford: IRL Press.

Tan, C. -T. (1990). Beverage emulsions. In K. Larsson, \& S. E. Friberg (Eds.). Food emulsions (2 $2^{\text {nd }}$ ed.) (pp 445-478). New York: Marcel Dekker.

Trubiano, P. C. (1995). The role of specialty food starches in flavor emulsions. Flavor Technology. Washington., D. C: ACS Symposium Series, 610, American Chemical Society.

Ward-Smith, R. S., Hey, M. J., \& Mitchell, J. R. (1994). Protein-polysaccharide interaction at oil-water interface. Food Hydrocolloids, 8, 309-315. http://dx.doi:10.1016/S0268-005X(09)80343-3

Williams, P. A., Phillips, G. O., \& Randall, R. C. (1990). Structure-function relationships of gum Arabic. In. G. O. Phillips, D. J. Wedlock \& P. A. Williams (Eds.). Gums and Stabilizers for the Food Industry, 5, 25-36. Oxford: IRL Press.

Table 1. Composition of prepared emulsion concentrates

\begin{tabular}{|l|c|c|c|c|}
\hline \multirow{2}{*}{ Emulsifiers (gums and protein) } & \multicolumn{2}{c|}{ Batch No.1 } & \multicolumn{2}{c|}{ Batch No.2 } \\
\cline { 2 - 5 } & Emulsifier (\%) & Oil (\%) & Emulsifier (\%) & Oil (\%) \\
\hline Gum Arabic & 10 & 10 & 10 & 20 \\
\hline Starch & 10 & 10 & 10 & 20 \\
\hline Soy protein isolate (SPI) & 10 & 10 & 10 & 20 \\
\hline Texture modifiers & 0.1 & 5 & 0.10 & 10 \\
\hline Carrageenan & 0.025 & 5 & 0.025 & 10 \\
\hline Tragacanth & \multicolumn{5}{|c|}{} \\
\hline Protein and texture modifier mixtures & 5 & $10+0.10$ & 10 \\
\hline SPI + Carrageenan & $10+0.1$ & 5 & $10+0.025$ & 10 \\
\hline SPI + Tragacanth & $10+0.025$ & 5
\end{tabular}


Table 2. Droplet size distribution and zeta potential of prepared emulsions concentrates

\begin{tabular}{|c|c|c|}
\hline Emulsifier/ Oil ratio (\%) & Zeta potential & Droplet size distribution $(\mu \mathrm{m})^{*}$ \\
\hline \multicolumn{3}{|c|}{ Emulsifiers (gums and protein) } \\
\hline \multicolumn{3}{|l|}{ Gum Arabic } \\
\hline $10: 10$ & $-16.9 \pm 0.23$ & $0.70(100 \%) \mathrm{a}$ \\
\hline 10:20 & $-18.5 \pm 0.56$ & $1.45(100 \%) b$ \\
\hline \multicolumn{3}{|l|}{ Starch } \\
\hline 10:10 & $-10.3 \pm 0.1$ & 0.40 (90.3\%); $0.77(9.7 \%)$ a \\
\hline 10:20 & $-12.1 \pm 0.45$ & $0.45(100 \%) \mathrm{a}$ \\
\hline \multicolumn{3}{|l|}{ Soy protein isolate (SPI) } \\
\hline $10: 10$ & $-16.1 \pm 0.25$ & $0.1(15.6 \%) ; 0.71(84.4 \%) \mathrm{a}$ \\
\hline 10:20 & $-16.1 \pm 0.15$ & $0.08(9.9 \%) ; 0.49(26 \%) ; 4.17(64 \%) b$ \\
\hline \multicolumn{3}{|l|}{ Texture modifiers } \\
\hline \multicolumn{3}{|l|}{ Tragacanth } \\
\hline $0.025: 5$ & $-33.4 \pm 0.51$ & $0.08(0.9 \%) ; 0.5(52.7 \%) ; 1.8(46.5 \%)$ a \\
\hline $0.025: 10$ & $-36.4 \pm 0.31$ & $0.7(47.5 \%) ; 4.4(52.5 \%) \mathrm{b}$ \\
\hline \multicolumn{3}{|l|}{ Carrageenan } \\
\hline $0.1: 5$ & $-37.3 \pm 0.12$ & $0.09(0.5 \%) ; 0.5$ (48.8\%); $1.7(46.6 \%) ; 4.7(4.1 \%) \mathrm{a}$ \\
\hline $0.1: 10$ & $-39.9 \pm 0.42$ & $0.07(3.7 \%) ; 0.5(50.8 \%) ; 2.0(45.5 \%) \mathrm{b}$ \\
\hline \multicolumn{3}{|c|}{ Protein and texture modifier mixtures } \\
\hline \multicolumn{3}{|l|}{ SPI + Tragacanth } \\
\hline 10:0.025:5 & $-15.9 \pm 0.49$ & $0.11(12.9 \%) ; 0.6(87.1 \%) \mathrm{a}$ \\
\hline 10:0.025:10 & $-15.4 \pm 0.35$ & 0.09 (8.7\%); $0.6(63.9 \%) ; 1.7(10.8 \%) ; 3.5(16.6 \%) b$ \\
\hline \multicolumn{3}{|l|}{ SPI + Carrageenan } \\
\hline $10: 0.1: 5$ & $-20.4 \pm 0.65$ & $0.7(2.1 \%) ; 0.5(15.5 \%) ; 2.1(35 \%) ; 6.1(43.4 \%)$ a \\
\hline 10:0.1:10 & $-15.1 \pm 0.55$ & $0.58(1.9 \%) ; 3.5(95.9 \%) ; 21.3(2.2 \%) \mathrm{b}$ \\
\hline
\end{tabular}

* Droplet size distribution percentage represents percentage of sample volume occupied by particles of similar average size. Zeta potential values are mean and standard deviation of triplicate measurements. The letters (a and b) within the row indicate significant $(\mathrm{p}<0.05)$ difference for the same hydrocolloid at different oil ratios. 
Table 3. Color and viscosity measurements of prepared emulsion concentrates

\begin{tabular}{|c|c|c|c|c|c|c|}
\hline \multirow{2}{*}{$\begin{array}{l}\text { Emulsifier/Oil ratio } \\
(\%)\end{array}$} & \multicolumn{5}{|c|}{ Color values } & \multirow[t]{2}{*}{ Viscosity (Pa.s) } \\
\hline & $L$ & $a$ & $b$ & $\Delta E$ & Chroma & \\
\hline Cow milk (3.25\%) & 77.87 & -1.45 & 6.66 & & & \\
\hline \multicolumn{7}{|c|}{ Emulsifiers (gums and protein) } \\
\hline \multicolumn{7}{|l|}{ Gum Arabic } \\
\hline 10:10 & 84.97 & -0.21 & 12.36 & $9.19 \pm 0.003$ & $12.36 \pm 0.04$ & $0.63 \pm 0.0034$ \\
\hline $10: 20$ & 85.02 & -0.21 & 16.10 & $11.87 \pm 0.07$ & $16.02 \pm 0.14$ & $0.74 \pm 0.0029$ \\
\hline \multicolumn{7}{|l|}{ Starch } \\
\hline $10: 10$ & 90.80 & -1.53 & 12.63 & $14.24 \pm 0.01$ & $12.72 \pm 0.04$ & $0.88 \pm 0.0031$ \\
\hline 10:20 & 93.10 & -1.28 & 14.71 & $17.22 \pm 0.02$ & $14.76 \pm 0.13$ & $0.95 \pm 0.0028$ \\
\hline \multicolumn{7}{|l|}{ Soy Isolate (SPI) } \\
\hline $10: 10$ & 89.53 & 0.52 & 12.20 & $13.06 \pm 0.03$ & $12.21 \pm 0.04$ & $1.02 \pm 0.0025$ \\
\hline 10:20 & 77.17 & 0.20 & 11.30 & $4.98 \pm 0.09$ & $11.30 \pm 0.09$ & $1.47 \pm 0.0020$ \\
\hline \multicolumn{7}{|l|}{ Texture modifiers } \\
\hline \multicolumn{7}{|l|}{ Tragacanth } \\
\hline $0.025: 5$ & 92.29 & -2.23 & 15.34 & $12.15 \pm 0.08$ & $15.50 \pm 0.01$ & $0.90 \pm 0.0051$ \\
\hline $0.025: 10$ & 84.31 & -2.67 & 16.79 & $16.85 \pm 0.03$ & $17.00 \pm 0.03$ & $1.07 \pm 0.0049$ \\
\hline \multicolumn{7}{|l|}{ Carrageenan } \\
\hline $0.1: 5$ & 88.33 & -1.93 & 9.14 & $10.76 \pm 0.14$ & $9.34 \pm 0.14$ & $1.07 \pm 0.0048$ \\
\hline $0.1: 10$ & 79.16 & -2.49 & 19.87 & $13.31 \pm 0.12$ & $20.03 \pm 0.13$ & $2.28 \pm 0.013$ \\
\hline \multicolumn{7}{|c|}{ Protein and texture modifier mixtures } \\
\hline \multicolumn{7}{|l|}{ SPI + Tragacanth } \\
\hline $10: 0.025: 5$ & 81.97 & 0.67 & 10.38 & $5.93 \pm 0.04$ & $10.40 \pm 0.01$ & ND \\
\hline 10:0.025:10 & 84.13 & 0.17 & 9.79 & $7.19 \pm 0.05$ & $9.79 \pm 0.09$ & ND \\
\hline \multicolumn{7}{|l|}{ SPI+ Carrageenan } \\
\hline $10: 0.1: 5$ & 80.30 & 0.65 & 11.12 & $5.50 \pm 0.005$ & $11.14 \pm 0.02$ & ND \\
\hline 10:0.1:10 & ND & ND & ND & ND & ND & ND \\
\hline
\end{tabular}

The $\mathrm{L}, \mathrm{a}, \mathrm{b}$ values are tristimulus values. " $\mathrm{L}$ " denotes lightness-to-darkness from 100 to 0 units, respectively. "'a" represents redness $(+a)$ to greenness $(-a)$, and " $b$ " represents yellowness $(+b)$ to blueness $(-b)$. ND: not determined (the emulsion was very thick and could not be homogenized). Values are means and standard deviation of triplicate measurements. 


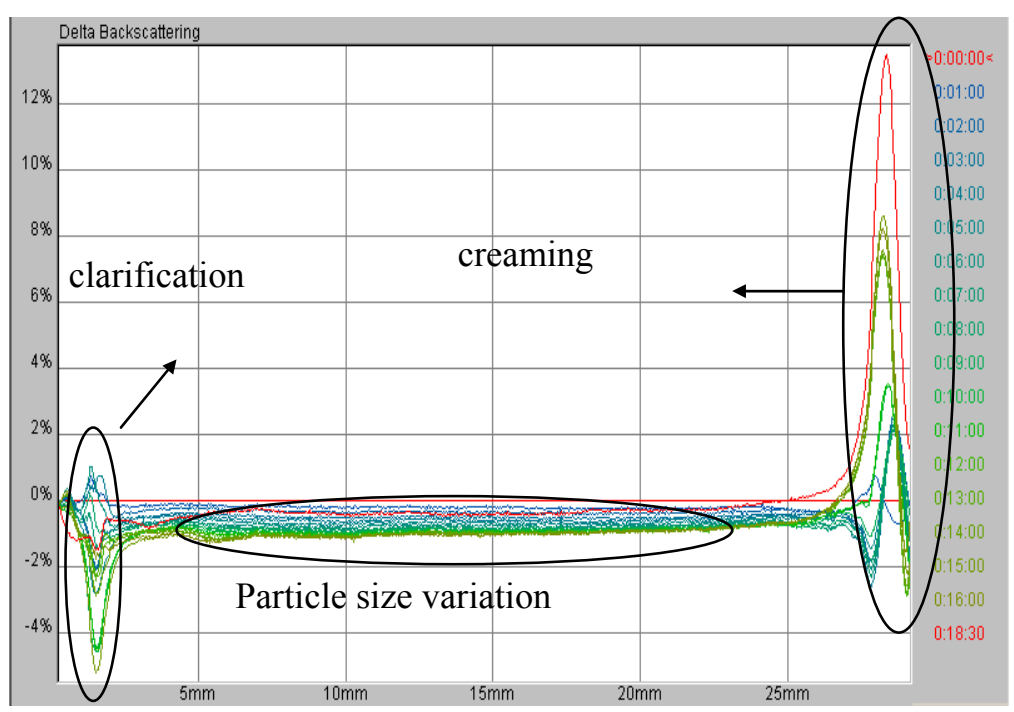

Figure 1. Typical instability phenomenon encountered in emulsions (reproduced with permission from Bru et al., 2004) 

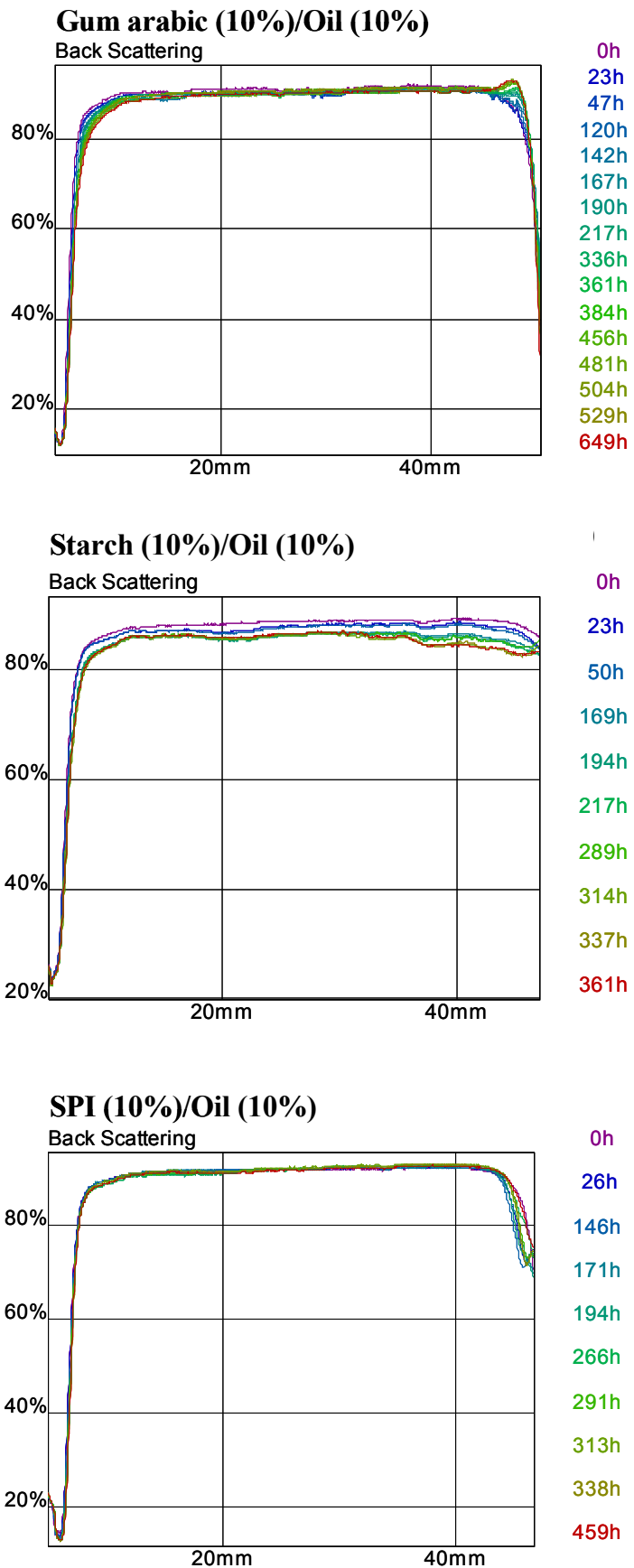

Gum arabic (10\%)/Oil (20\%)

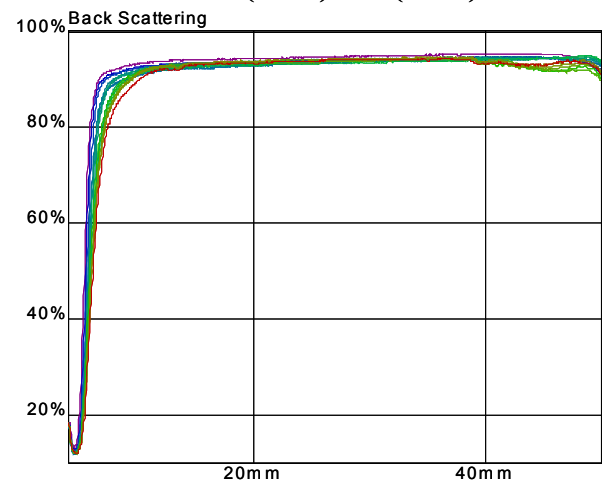

$0 h$
$23 h$
$47 h$
$120 h$
$142 h$
$167 h$
$190 h$
$217 h$
$336 h$
$361 h$
$384 h$
$456 h$
$481 h$
$504 h$
$529 h$
$649 h$

\section{Starch (10\%)/Oil (20\%)}

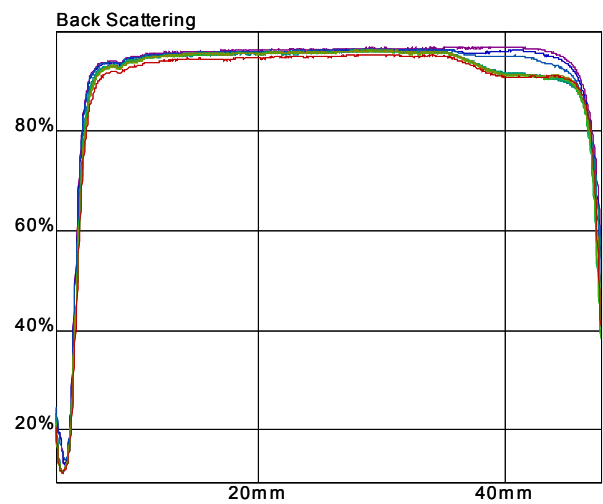

Oh

$23 \mathrm{~h}$

$50 \mathrm{~h}$

$169 \mathrm{~h}$

$194 \mathrm{~h}$

$217 \mathrm{~h}$

$289 \mathrm{~h}$

$314 \mathrm{~h}$

$337 \mathrm{~h}$

$361 \mathrm{~h}$

$482 \mathrm{~h}$

\section{SPI (10\%)/Oil (20\%)}

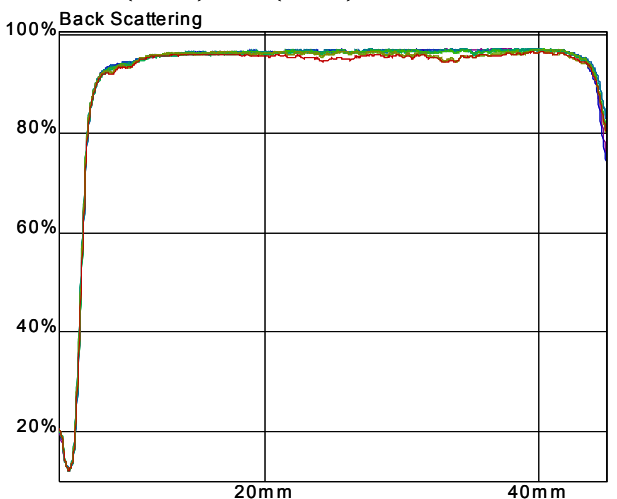

Figure 2. Backscattering profiles of concentrated emulsions stabilized with gum arabic, starch and SPI at emulsifier/oil ratios of 10:10 and 10:20\% \% (w/v) 


\section{Carrageenan (0.1\%)/Oil (10\%)}

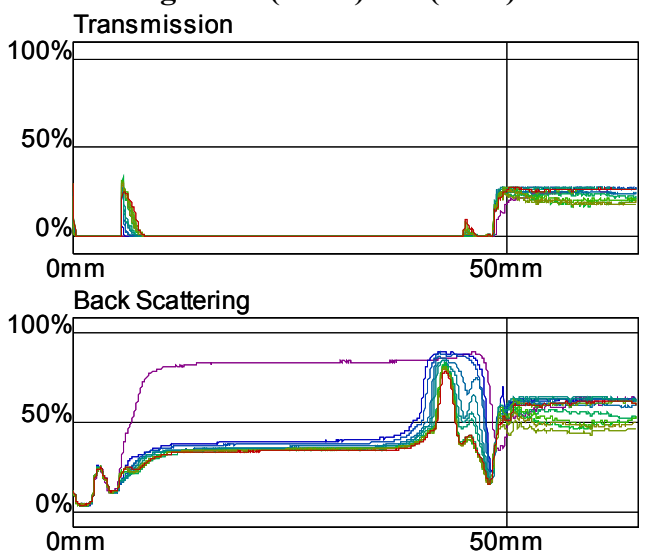

SPI (10\%) + Carr (0.1\%)/Oil (10\%)

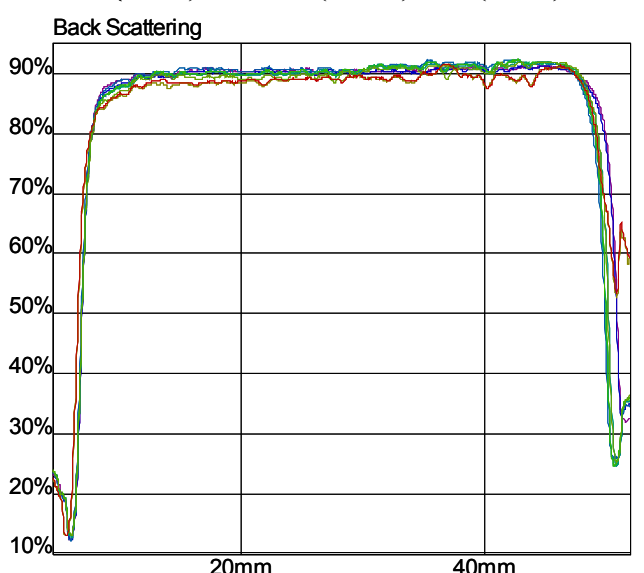

SPI (10\%) + Carr (0.1\%)/Oil (5\%)

Back Scattering

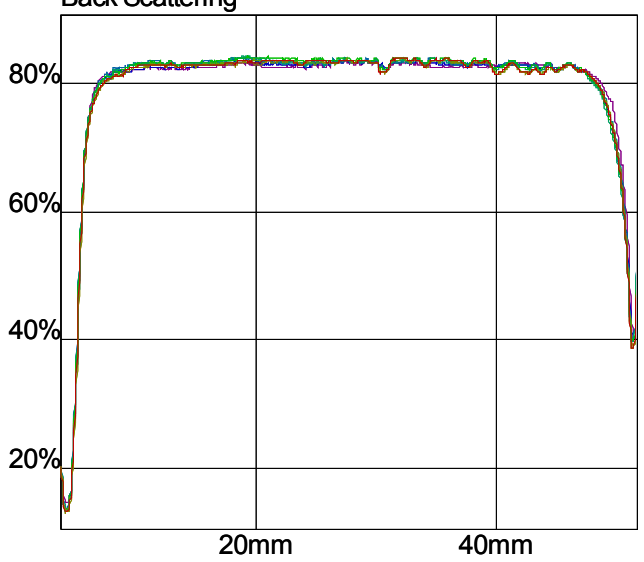

Tragacanth (0.025\%)/Oil (10\%)

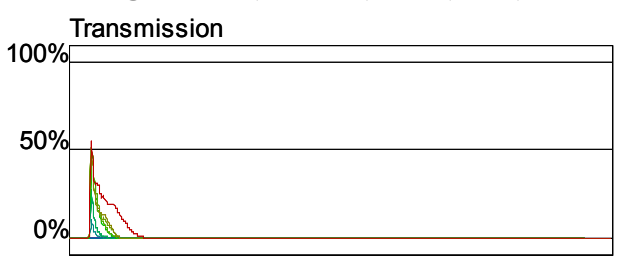

Oh

$24 \mathrm{~h}$

$48 \mathrm{~h}$

$75 \mathrm{~h}$

$194 \mathrm{~h}$

$219 \mathrm{~h}$

$242 \mathrm{~h}$

$314 \mathrm{~h}$

$339 \mathrm{~h}$

$362 \mathrm{~h}$

$386 \mathrm{~h}$

$507 \mathrm{~h}$

$$
20 \mathrm{~mm}
$$

$40 \mathrm{~mm}$

\section{SPI (10\%) + Trag (0.025)/Oil (10\%)}

Oh

$24 \mathrm{~h}$

$47 \mathrm{~h}$

$119 \mathrm{~h}$

$144 \mathrm{~h}$

$167 \mathrm{~h}$

$191 \mathrm{~h}$

$312 \mathrm{~h}$

$360 \mathrm{~h}$

$385 \mathrm{~h}$

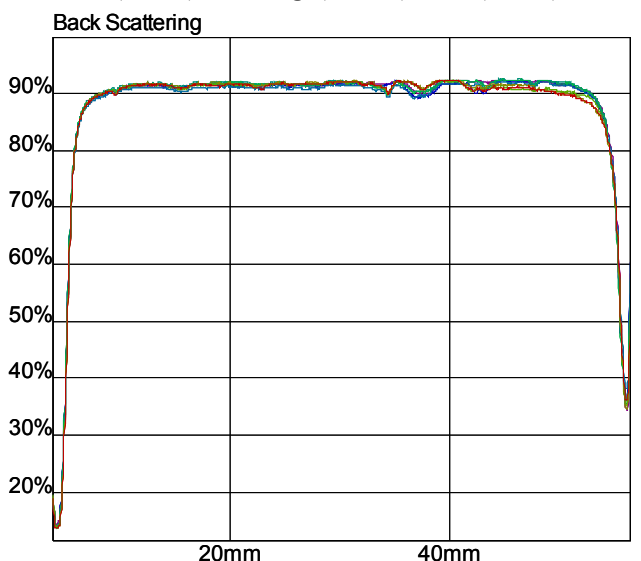

SPI (10\%) + Trag (0.025\%)/Oil (5\%)

Oh
$22 h$
$94 h$
$119 h$
$142 h$
$166 h$
$287 h$
$336 h$
$360 h$

\section{Back Scattering}

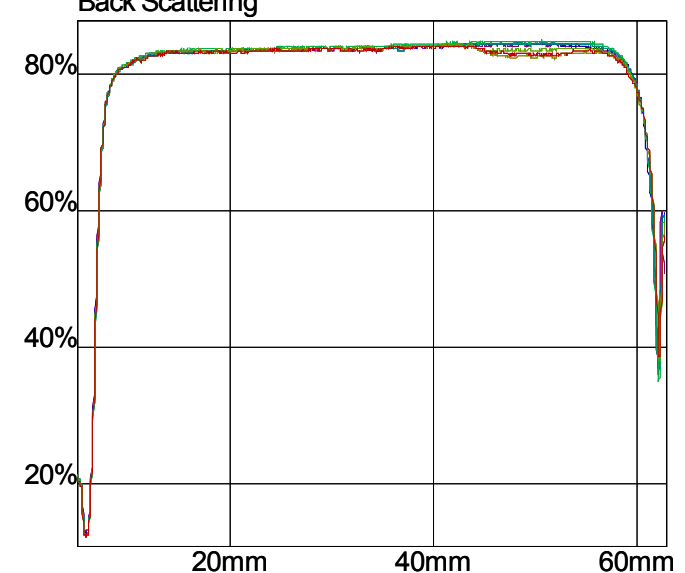

Oh

$72 \mathrm{~h}$

$97 \mathrm{~h}$

$119 \mathrm{~h}$

$144 h$

$265 h$

$313 h$

$337 \mathrm{~h}$

Figure 3. Backscattering profiles of concentrated emulsions stabilized with tragacanth and carrageenan alone and as a mixture with SPI at both 5 and $10 \%$ oil concentration 


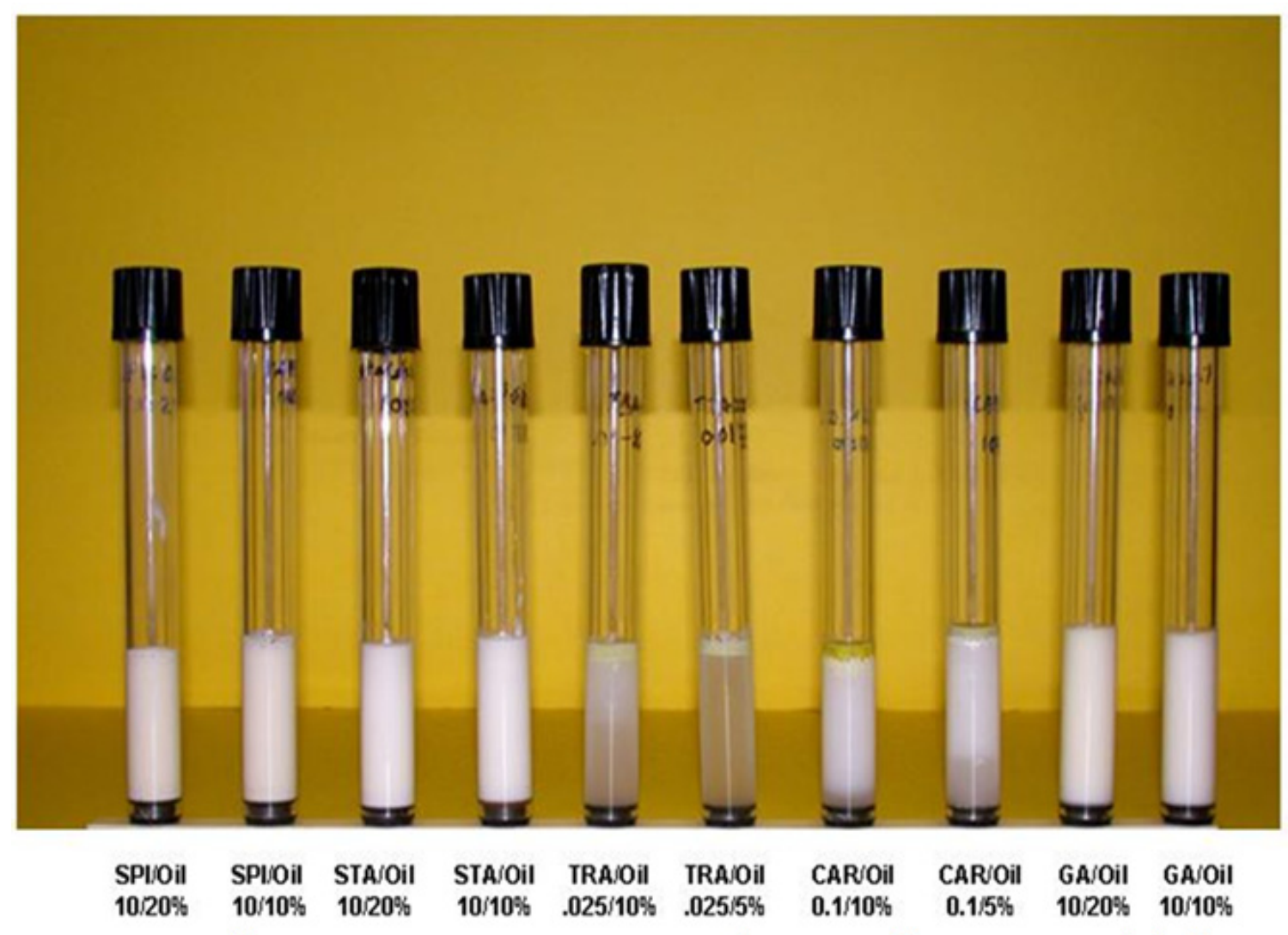

GA: gum arabic; CAR: carrageenan; TRA: tragacanth; STA: starch; SPI: soy protein isolate

Figure 4. Picture showing the physical stability of the prepared emulsion concentrates 